Revista Latinoamericana de la Papa 22 (1): 58 - 66

ISSN: $1853-4961$

http://www.papaslatinas.org/ojs/index.php/index/oai

\title{
Ampliando la frontera agrícola de la papa (Solanum tuberosum L.) para disminuir los efectos del cambio climático
}

\author{
J. Gabriel ${ }^{1 / *}$, J.I. Ruiz de Galarreta ${ }^{2}$, X. Cuesta $^{3}$, M. Huarte ${ }^{4}$, N. Zuñiga ${ }^{5}$, M. Mayer de

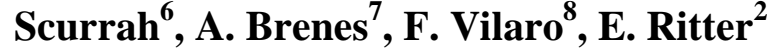

Recibido: $16 / 02 / 2018$

Aceptado: 04/05/2018

Acceso en línea: Junio 2018

\section{Resumen}

La mayoría de los cultivares tradicionales de papa no están adaptadas a las condiciones del cultivo provocadas por el cambio climático, que hacen disminuir drásticamente los rendimientos e incluso perder completamente la cosecha en muchos lugares desfavorecidos. En países en vías de desarrollo, como en Latinoamérica, esta situación afecta a la base alimentaria de las comunidades, y al sostenimiento económico y social; los agricultores optan por migrar en búsqueda de otros medios de subsistencia. Ante esta problemática, se estableció un consorcio de ocho instituciones reconocidas de siete países para identificar y desarrollar cultivares de papa adaptados al cambio climático y desarrollar metodologías y herramientas moleculares eficientes que aceleren este proceso. El proyecto logró cultivares con mejor adaptación a condiciones ambientales adversas en zonas productoras y zonas desfavorecidas. Se mejoró la competitividad del cultivo de la papa, que aumentó la superficie de su cultivo, y se diversificó la producción agraria, asegurando el suministro de alimentos en zonas deprimidas. Los agricultores cuentan con cultivares, con buena adaptación a los cambios en temperatura, precipitación, y mayor resistencia al tizón tardío (Phytophthora infestans). Los investigadores disponen de metodologías adecuadas para la evaluación de resistencias a estreses bióticos y abióticos y disponen de marcadores moleculares útiles para predecir el comportamiento agronómico y la adaptación.

Palabras clave adicionales: Germoplasma, marcadores moleculares, competitividad, resistencia, agricultores.

Autor para correspondencia: julio.gabriel@unesum.edu.ec

Fundación PROINPA, Bolivia. Actualmente Universidad Estatal del Sur de Manabí, Jipijapa, Manabí, Ecuador.

NEIKER Tecnalia, España.

INIAP, Ecuador.

INTA, Argentina.

INIA. Perú.

Grupo Yanapay, Perú.

UCR, Costa Rica.

INIA, Uruguay. 



\section{Expanding the agricultural frontier of the potato (Solanum tuberosum L.) to reduce the effects of climate change}

\section{Summary}

A temporary immersion system was tested to accelerate the procurement of pre-basic seed category of two varieties for agroindustry, Superchola and Diacol-Capiro (Solanum tuberosum L.) in addition to the autotrophic hydroponic system. The results of the proposed system presented several advantages compared to in vitro produced seed and semi-hyroponic seedlings. The vegetative part was increased in the total number of node segments obtained by the bioreactor, 322 and 264 for Superchola and Diacol-Capiro respectively. These values corresponded to the production of 81 test tubes $(1,8 \times 14 \mathrm{~cm})$, which occupied an area of $2041,2 \mathrm{~cm}^{2}$. The production cycle was also shorter than the traditional in vitro agar culture system in fifteen days. The multiplication rates for Superchola and Diacol-Capiro were 1:9 and 1:8. The production rate per area was $>366$ minitubers per $\mathrm{m}^{2}$ in Superchola and 225 minituber per $\mathrm{m}^{2}$ in Diacol-Capiro. The average yield of $3.75 \mathrm{~kg} . \mathrm{m}^{-2}$ is higher than those obtained in vitro and semi-hydroponic seedlings. Superchola achieved the best response with superior yields (tuber quantity) 20\% over Diacol-Capiro. The cost/profit ratio of 1.27 defined Superchola as the most profitable under the proposed seed production system with a return of 0.27 USD per invested dollar. This system can be adapted for commercial in vitro potato seed propagation.

Additional Keywords: bioreactor, substrate, micropropagation, minitubers, Solanum tuberosum.

\section{Introducción}

La papa (Solanum tuberosum L.) tiene un papel clave en la cadena alimenticia global. Después de los cereales es el alimento más importante en el mundo, debido a su alta productividad y su elevado valor nutricional. Su producción alcanzó un record de 320 millones de toneladas en el año 2007. La papa se cultiva en casi todos los países, y su producción - así como su consumo - está incrementándose en los países en desarrollo. La papa es una valiosa herramienta en la lucha contra el hambre y la pobreza, que es una de las razones por lo que la ONU declaró el 2008 como Año Internacional de la Papa (AIP). Este evento atrajo la atención hacia el papel crucial que la "humilde papa" tiene en la agricultura, la economía y la seguridad alimentaria del mundo (Devaux et al. 2010). La mayor parte de los cultivos están afectados por el "cambio climático" que además del calentamiento global conlleva un aumento de eventos climáticos extremos (incluyendo periodos de calor o frío, sequía e inundaciones) y cambios en la distribución geográfica de las precipitaciones. Los estreses abióticos relacionados con dicho cambio representan una limitación crítica y una amenaza mayor para la agricultura sostenible y la seguridad alimentaria. Por lo tanto un desafío importante para las próximas décadas será el de mantener e incluso aumentar la producción de alimentos en estas condiciones. Ante estos escenarios, es imprescindible tomar medidas preventivas y de adaptación para mitigar los efectos adversos del cambio climático sobre los sistemas de producción basados en papa.

La base genética para la búsqueda de características deseables que determinen resistencia y/o tolerancia a estreses abióticos y bióticos se encuentra en la gran diversidad de papa presente en los países. Estos materiales constituyen uno de los más valiosos recursos fitogenéticos de la zona Andina para la seguridad 
alimentaria y para afrontar el cambio climático. Sin embargo, para su mejor aprovechamiento se requieren realizar evaluaciones sistemáticas de estos materiales y combinar esfuerzos para acelerar la obtención de nuevas alternativas tecnológicas.

Aunque existen técnicas agronómicas para paliar los efectos de los estreses, finalmente es necesario desarrollar nuevos cultivares adaptados a las condiciones adversas, aprovechando la biodiversidad natural existente en las especies. Particularmente, los marcadores moleculares son herramientas valiosas para acelerar programas de mejora genética y para evaluar la biodiversidad funcional (Ritter et al.2005). Se han identificado

genes candidatos y marcadores para resistencia a estreses abióticos (Shinozaki et al. 2003, Shrinivasrao et al. 2008). La papa es muy sensible a estreses abióticos causando importantes reducciones en el rendimiento (Porter et al. 1999), ya que su sistema radicular no es muy denso y es superficial (Jefferies 1993, Fabiero et al. 2001) y las heladas son capaces de destruir el cultivo.

La mayoría de los cultivares tradicionales de papa no están adaptadas a las condiciones del cultivo provocados por el cambio climático, que hacen disminuir drásticamente los rendimientos e incluso perder completamente la cosecha en muchos lugares desfavorecidos. Dicho cambio climático provoca también distorsiones en la distribución geográfica de plagas y enfermedades. El tizón tardío (Phytophthora infestans) representa la enfermedad más peligrosa para la papa con efectos devastadores que causa. Esta enfermedad causa daños en regiones que nunca habían conocido esta enfermedad (Haas et al. 2009).

En países en vías de desarrollo, y particularmente en Latinoamérica, esta situación afecta no solo la base alimentaria de las comunidades, sino también a su sostén económico y social, ya que los agricultores optan por migrar en búsqueda de otros medios de subsistencia.

Perú es el tercer país más vulnerable ante los riesgos climáticos del mundo -es solo superado por Honduras y Bangladesh-, por lo que las consecuencias del cambio climático como heladas, sequías serán más intensos y frecuentes y sus efectos perturbarán la disponibilidad de alimentos como la papa, alimento principal en la zona andina, si no estamos preparados para el caso. Ante esta problemática se ha establecido un consorcio de instituciones reconocidas para identificar y desarrollar germoplasma de papa adaptado al cambio climático y desarrollar metodologías y herramientas moleculares eficientes que aceleren este proceso. Los socios del consorcio se conocen desde muchos años y ya han colaborando en el pasado en diferentes proyectos I+D. Todos los socios son miembros de la "Red Iberoamericana de Innovación en Mejoramiento y Diseminación de la Papa " - RED LATINPAPA".

\section{Materiales y métodos}

El proyecto se estructuró en diferentes componentes que conllevaron varias actividades en cada caso.

\section{Evaluaciones fenotípicas}

Se realizó evaluaciones fenotípicas de resistencias/tolerancias a los estreses: sequía, calor y frío y resistencias al tizón tardío en cultivares comerciales, papas nativas, clones de mejora y germoplasma silvestre con el fin de identificar cultivares potenciales adaptados a condiciones climáticas adversas y progenitores útiles para los programas de mejora genética (Cicore et al. 2012). Las evaluaciones se realizaron midiendo parámetros indirectos mediante bioensayos y analizando el desarrollo y la producción en ensayos en invernadero o campo bajo condiciones estresadas y sin estresar, y se desarrolló metodología adecuada de evaluación 
eficiente de adaptación a estreses abióticos. Los socios realizaron más de 60 ensayos en campo o invernadero para evaluar las resistencias al frio, calor, sequía y Phytophthora infestans a través del comportamiento agronómico en condiciones de estrés y/o midiendo diferentes parámetros indirectos en germoplasma variado.

\section{Evaluación de marcadores moleculares}

Se evaluaron marcadores específicos de genes candidatos para estreses bióticos y abióticos que ya están disponibles y se caracterizó la composición alélica de los cultivares y germoplasma. Cruzando los datos fenotípicos y los datos moleculares, se detectaron mediante técnicas de "Mapeo por Asociación" marcadores moleculares específicos que sirven para la selección asistida de material genético adaptado al cambio climático (Ritter et al. 2008, Hernández et al. 2009, Lopez- Pardo et al. 2013, Lopez-Pardo et al. 2013). De esta forma se agiliza el proceso de selección y la obtención de nuevos cultivares con características superiores.

\section{Pre-mejoramiento}

Se realizó actividades de mejoramiento genético integrando los resultados de los componentes anteriores para combinar características favorables y generar de esta forma cultivares adaptados. Estas actividades incluían la realización de numerosos cruzamientos y evaluación de progenies, evaluación de resistencias en genotipos selectos aplicando la selección asistida por marcadores (Gabriel et al. 2012, Porras Martínez \& Brenes Angulo 2014).

\section{Difusión tecnológica}

Se realizaron numerosas actividades de difusión, transferencia y demostración para lograr la implantación efectiva de los resultados obtenidos tanto en el mundo científico como a nivel de agricultores y sus asociaciones. Para ello se estableció una página WEB del proyecto con una
Base del Conocimiento integrada y se han realizado numerosas publicaciones, contribuciones a congresos, cursos de formación, talleres, ferias y días de campo así como campos demostrativos.

\section{Resultados}

Los socios del proyecto realizaron más de 60 ensayos en invernadero bajo condiciones controladas o en campo en diferentes entornos ambientales adversos y en ambientes sin estresar. Se evaluaron las resistencias al frio, calor, sequía y Phytophthora infestans a través del comportamiento agronómico en condiciones de estrés y/o midiendo diferentes parámetros indirectos en germoplasma variado. Acorde con los Indicadores Objetivamente Verificables (IOV) y los entregables, los socios identificaron genotipos prometedores para cada factor de estrés. Estos genotipos (cultivares comerciales y clones de mejora) sirven tanto para el cultivo en las correspondientes condiciones adversas, como para genitores en los programas de mejora genética. También se ha compilado una colección de protocolos y métodos para evaluar la resistencia a estos estreses. Los socios han evaluado su idoneidad en cada caso, y han realizado algunas modificaciones para optimizar la metodología. Muchas veces no hubo correlaciones significativas entre los parámetros indirectos y el comportamiento agronómico en condiciones de estrés, lo cual se debe a la diversidad del material genético. Por lo tanto se concluye que la evaluación agronómica es el método más seguro para evaluar resistencias/tolerancias a estreses abióticos.

Se identificaron 58 genes candidatos y se secuenció sus amplicones en una colección de 150 genotipos utilizando dos plataformas diferentes, Roche 454 y Ion Torrent. Se inició el Mapeo por Asociación, que tiene cuatro pasos: 1) Análisis de la estructura de la población, 
2) Preparación de los Amplicones, 3) Detección de SNPs y patrones, y 4) Análisis estadístico del Mapeo Asociativo. Para los dos últimos pasos se desarrollo un Software apropiado. Se dispone de toda la información sobre los alelos de los 18 genes candidato de resistencia/tolerancia que existen en la población y de las secuencias de los alelos y sus frecuencias en las entradas de las colecciones de papas evaluadas, así como del grado de heterocigosidad de las entradas. Se realizaron diferentes tipos de análisis: análisis de los efectos de los alelos, análisis de efectos de combinaciones de alelos y análisis homo versus heterocigoto. Se han encontrado numerosas asociaciones de uno $\mathrm{u}$ otro tipo. Por otra parte los socios han extraído el ADN de algunas de sus accesiones y enviaron estos ADNs a NEIKER. Algunos socios aplicaron con éxito algunos marcadores conocidos de resistencia a Phytophthora y otros estreses bióticos.

Se realizaron miles de cruzamientos por los diferentes socios para combinar características favorables de los parentales. Los socios también evaluaron numerosas progenies para seleccionar genotipos prometedores. Se identificaron 280 progenitores útiles y 350 progenies prometedoras, para los programas de mejoramiento genético como base para generar cultivares con características superiores de adaptación en el próximo futuro. Se identificó en las progenies ensayadas genotipos con tolerancias/resistencias combinadas que muestran un comportamiento agronómico superior.

Se utilizaron los marcadores moleculares para clasificar a los parentales y algunos genotipos prometedores de las progenies. Para implementar la selección asistida en los programas de mejora genética, los socios enviaron ADN de diferentes entradas y datos agronómicos a NEIKER. Los ADNs se procesaron por secuenciación de amplicones con los genes candidatos detectados. Se validaron resultados previos y se detectaron tanto nuevos alelos de genes candidatos en el material de los socios, como la presencia de alelos superiores en germoplasma con mejor comportamiento agronómico.

Se estableció la página WEB del proyecto, la cual contiene todos los resultados obtenidos por los socios. La página se ha actualizado anualmente. Incluye una compilación de protocolos y métodos para la evaluación de los diferentes estreses abióticos y para resistencia a $P$. infestans (tizón tardío; rancha).

Los socios presentaron los resultados del proyecto en varias ponencias y póster en diferentes congresos nacionales e internacionales, 41 en total. Se realizó 26 publicaciones, inclusive una nota de prensa. Se impartió dos cursos de Bioinformática y un curso internacional sobre manejo del cultivo. Setenta y cuatro actividades de transferencia al sector se realizaron por los diferentes socios a través de visitas de campo, ferias y charlas a agricultores, semilleristas y medios de comunicación, incluyendo el establecimiento de numerosos campos demostrativos. También se realizó el IV Congreso Iberoamericano sobre I+D en la papa en 2013 en Riobamba (Ecuador) con el fin de difundir los resultados del proyecto.

Las actividades de $\mathrm{I}+\mathrm{D}+\mathrm{T}$ se coordinaron a través de una Reunión inicial en Cochabamba (Bolivia) y reuniones anuales en San José (Costa Rica), Lima (Perú) y Riobamba (Ecuador). En estas reuniones se presentaron las actividades realizadas y los resultados obtenidos. Se explicaron los procedimientos administrativos y se dieron instrucciones para realizar la justificación de los gastos y aportaciones de contrapartida, la preparación del ISTA y del POA. Durante el avance del proyecto se tuvieron comunicaciones vía correo electrónico sobre el desarrollo de las 
actividades y para la preparación y elaboración de informes de avances y de los informes anuales de ejecución del proyecto.

\section{Discusión}

La papa es uno de los cultivos alimenticios más importantes en el mundo, por su alto valor nutritivo, adaptabilidad a diversos climas y sistemas de cultivo. El cultivo de papa es afectado por un sin número de limitantes de origen biótico y abiótico, entre los que están, sequías y heladas, las cuales se han hecho más evidentes por efectos del cambio climático. La helada influye en el desarrollo normal de la planta y puede llegar a reducir el rendimiento un $30 \%$ y hasta $100 \%$, dependiendo de la intensidad y del tiempo de exposición. Reconociendo la importancia de las heladas y de no conocer genotipos resistentes a este factor se planteó el objetivo de identificar genotipos con resistencia al estrés causado por bajas temperaturas para utilizarlos directamente o como progenitores en el programa de mejora genética para el desarrollo de nuevos cultivares con resistencia a las heladas.

Según la Organización de las Naciones Unidas para la Alimentación y la Agricultura (2008), la producción de alimentos de los países en desarrollo se lleva a cabo en un $60 \%$ en tierras que dependen de lluvia, teniendo solo un $40 \%$ restante regadío, constituyéndose el agua en requisito indispensable para alcanzar y preservar el desarrollo sostenible.

Se prevé que estos países aumentarán sus tierras de regadío pasando de los 248 millones de hectáreas actuales a 311 millones para el 2030, afirmando que el riego aumenta la producción entre un 100 y el $400 \%$ (Organización de las Naciones Unidas para la Alimentación y la Agricultura 2008).

Hargreaves \& Merkley (2000), precisan que el requerimiento hídrico de un cultivo está determinado por el potencial de evaporación climático, de las características de las plantas y de los factores que influyen en el crecimiento de la planta.

La Organización de las Naciones Unidas para la Alimentación y la Agricultura (2008), señala que algunos cultivares modernos de papa son sensibles a la falta de agua y necesitan una irrigación frecuente y superficial. El cultivo de papa de 120 a 150 días consume de 500 a 700 $\mathrm{mm}$ de agua, y la producción dismunuye si no se aporta con más del $50 \%$ del total de agua disponible en el suelo durante el crecimiento.

Scott et al. (2004), mencionan que tanto los productores como los investigadores dan cuenta de un aumento del estrés hídrico, de cambios en la distribución e intensidad de las lluvias, de granizadas y heladas, fenómenos; extremos producto del cambio climático.

El Grupo Intergubernamental de Expertos sobre el Cambio Climático (2007), menciona que el cambio climático es un cambio en el estado promedio del clima, a lo largo del tiempo, generalmente cifrado en decenios o en períodos más largos debido a la variabilidad natural $o$ consecuencia de la actividad humana.

Estudios realizados por Watson et al. (1997), señalan que los principales efectos directos del cambio climático sobre los cultivos, serían principalmente la duración de los ciclos, alteraciones fisiológicas por exposición a temperaturas fuera del umbral permitido, deficiencias hídricas y respuestas a nuevas concentraciones de $\mathrm{CO} 2$ atmosférico.

En el proyecto se han identificado en cada país participante cultivares y germoplasma con elevadas resistencias $\mathrm{o}$ tolerancias a los estreses mencionados. La disponibilidad de cultivares apropiados para condiciones ambientales adversas mejora la competitividad del cultivo de la papa, aumenta la superficie de su cultivo, 
y diversifica la producción agraria, asegurando el suministro de alimentos en zonas deprimidas. El cultivo de cultivares adecuados aumenta los ingresos de los agricultores, contribuyendo de esta forma al desarrollo sostenible, a la seguridad y soberanía alimentaria, al incremento de la calidad de vida, y a la paz en esta región.

En nuestro proyecto nos centramos en la detección y el análisis de los efectos de los diferentes alelos de genes candidatos individuales e incluso se aplicó para detectar parentales o genotipos prometedores en progenies de cruces controlados. Sin embargo, sería interesante aplicar estos marcadores masivamente en programas completos de mejora genética y extendiendo los análisis al conjunto de marcadores para desarrollar modelos multi-marcadores apropiados de selección, y comparar los resultados obtenidos con aquellos de la mejora clásica. Genes candidatos a estreses abióticos y bióticos se publicaron en varios cultivos incluido la papa. Nosotros hemos explotado algunos de estos genes para nuestros fines. Sin embargo también hemos detectado nuevos genes candidatos aplicando técnicas como cDNA-AFLP diferencial.

Aparte de este enfoque que está basado en genes candidatos concretos cabe la posibilidad de utilizar masivamente marcadores al azar ("Candidate gene driven versus Random approach, GWAS, Genomic selection"), el cual recientemente está ganando importancia. Este enfoque alternativo se facilita por las posibilidades que ofrecen las tecnologías emergentes de secuenciación de nueva generación (NGS) y nuevas plataformas tecnológicas que se vienen desarrollando para ello.

\section{Conclusiones}

En el germoplasma de la papa existen aún fuentes de resistencia a estreses abióticos y bióticos desconocidos que se pueden explotar para aliviar las amenazas del cambio climático, ya que en todos los países de los socios del consorcio se encontraron genotipos con ciertos niveles de resistencia y/o tolerancia a estos estreses.

Los genes candidato detectados muestran diferencias significativas en los efectos de sus diferentes alelos para mantener el comportamiento agronómico en condiciones de estrés. Por lo tanto sirven para la selección asistida por marcadores y permiten acelerar los programas de mejora significativamente. Se recomienda su uso en los programas de mejora clásicos.

La metodología desarrollada o optimizada es apropiada para la detección de nuevas fuentes de resistencias/tolerancias a estreses abióticos o bióticos.

Las numerosas acciones de diseminación y transferencia de los resultados del proyecto fueron muy eficaces y tuvieron un impacto elevado como muestra las utilización de cultivares recomendados y el aumento de la superficie de su cultivo.

La estrategia y la metodología que se ha aplicado en este proyecto al cultivo de la papa es transferible de forma análoga a otros cultivos de interés.

\section{Conflictos de intereses}

Los autores del artículo presentado declaran que no existe ningún conflicto de intereses.

\section{Agradecimiento}

A todas las instituciones que conformaron el consorcio y a FONTAGRO por el financiamiento para desarrollar la investigación. Las opiniones expresadas en el mismo no reflejan necesariamente la opinión oficial de las instituciones.

\section{Referencias citadas}

Devaux, A.; Ordinola, M.; Hibon, A.; Flores, R. (2010). El sector papa en la región andina: Diagnóstico y elementos para una visión estratégica (Bolivia, 
Ecuador y Perú). Lima: Centro Internacional de la Papa.

Fabiero, C.; Martín de Santa Olalla, F.; \& De Juan, J. A. (2001). Yield and size of deficit irrigated potatoes. Agric. Water Manage, 48(3): 255-266. Disponible en http://www.sciencedirect.com/science/arti cle/pii/S0378-3774(00)00129-3

Organización de las Naciones Unidas para la Alimentación y la Agricultura (2008). El estado mundial de la agricultura y la alimentación. Organización de las Naciones Unidas para la Agricultura y la Alimentación. Roma: FAO.

Gabriel, J.; Ancasi, G.; Angulo, A.; Magne, J.; La Torre, J.; Mamani, P. (2012). Genetically- induced drought resistance in potato hybrids (Solanum tuberosum L.). Revista Latinoamericana de la Papa 17 (1): 97-124.

Haas, B. J., et al. (2009). Genome sequence and analysis of the Irish potato famine pathogen Phytophthora infestans, Nature 461: 393-398. Disponible en https://www.nature.com/articles/nature08 $\underline{358}$

Hargreaves, G.H. \& Merkley, G.P. (2000). Fundamentos del riego: un texto de tecnología aplicada para la enseñanza del riego a nivel intermedio. Littleton: Water Resources Publications,

Hernández, M.; Ruiz de Galarreta, J. I.; Ritter, E. (2009). Detección de genes candidato de resistencia a Phytophthora infestans, mediante tecnicas de expresión diferencial: cDNA-AFLP y microarrays. En E. Ritter \& J. I. Ruiz, Avances en Ciencia y Desarrollo de la Patata para una Agricultura Sostenible. (109-113). Vitoria: Servicio Central de Publicaciones del Gobierno Vasco.

Cicore, P. L.; Andreu, A.B.; Huarte, M. A. (2012). Reaction to late blight in response to nitrogen management in Argentine potato cultivars. Crop Protection 42: 69-73. Disponible en http://ri.conicet.gov.ar/handle/11336/1326 $\underline{2}$

Grupo Intergubernamental de Expertos sobre el Cambio Climático. (2007). Cambio climático 2007: Informe de síntesis. Contribución de los Grupos de trabajo I, II y III al Cuarto Informe de evaluación del Grupo Intergubernamental de Expertos sobre el Cambio Climático. Ginebra: IPCC.

Jefferies, R. A. (1993). Responses of potato genotypes to drought. 1. Expansion of individual leaves and osmotic adjustment. Ann. Appl. Biol. 122: 93104.

Lopez-Pardo, R.; Ruiz de Galarreta, J.I., \& Ritter, E. (2013). Housekeeping genes selection for QRT-PCR analysis in potato tubers under cold stress. Molecular Breeding 31: 39- 45.

Lopez-Pardo, R.; Barandalla, L.; Ritter, E.; \& Ruiz de Galarreta, J. I. (2013). Validation of molecular markers for pathogen resistance in potato. Plant Breeding 132: 246-251.

Porras-Martínez, C. \& Brenes-Angulo, A. (2014). Calidad de los tubérculos y componentes de rendimiento de híbridos F1 de papa (Solanum tuberosum). Agonomía Costarricence

39 (3): 37-46.

Disponible en https://revistas.ucr.ac.cr/index.php/agroco st/article/view/21788

Ritter, E.; Lucca, F.; Sánchez, I.; Ruiz de Galarreta, J.L.; Aragonés, A.; Castañón, S.; Bryan, G.; Waugh, R.; Lefebvre, V.; Rousselle-Bourgoise, F.; Gebhardt, C.; van Eck, H.; van Os, H.; Taco, J.; Bakker, J. (2005). Genomic resources in potato and possibilities for exploitation. En: Potato in progress (Eds.: Haverkort AJ \& PC Struik), Wageningen Academic Publishers, Holanda, pp 55-64.

Ritter, E.; Ruiz de Galarreta, J.I.; Van Eck, H.J.; Sánchez, I. (2008). 

Construction of a potato transcriptome map based on the cDNA-AFLP technique. Theor Appl. Genet. 116: 10031013. Disponible

en https://link.springer.com/article/10.1007/s 00122-008-0731-5

Scott, I. M.; Clarke, S. M.; Wood, J. E.; Mur, L. A. (2004). Salicylate accumulation inhibits growth at chilling temperature in Arabidopsis. Plant Physiol., 135(2): 10401049. Disponible en https://www.ncbi.nlm.nih.gov/pmc/articles /PMC514138/

Shinozaki, K.; Yamaguchi-Shinozaki, K.; Seki, M. (2003). Regulatory network of gene expression in the drought and cold stress responses. Curr Opin Plant Biol. 6(5): 410-417. Disponible en https://www.ncbi.nlm.nih.gov/pubmed/12 $\underline{972040}$
Shrinivasrao, P.; Vasquez, C.; Ulanov, A.; Schafleitner, R.; Tincopa, L.; Gaudin, A.; Nomberto, G.; Alvarado, C., Solis, C.; Avila, L.; Blas, R.; Ortega, O.; Solis, J.; Panta, A.; Rivera, C.; Samolski, I.;

Carbajulca, D.H.; Bonierbale, M.; Pati, A.; Heath, L.S.; Bohnert, H.J.; Grene, R. (2008). Molecular and physiological adaptation to prolonged drought stress in the leaves of two Andean potato genotypes. Functional Plant Biology 35: 669-688. Disponible en http://www.publish.csiro.au/fp/fp07293

Watson, R.; Zinyowera, M.; Moss, R.; Dokken, D. (1997). The regional impacts of climate change: an assessment of vulnerability. Summary for policymakers. Ginebra: IPCC. 